\title{
Hypertension among Danish seafarers
}

\section{Mingshan Tu, Jørgen Riis Jepsen}

Centre of Maritime Health and Society, Institute of Public Health, University of Southern Denmark, Esbjerg, Denmark

\section{ABSTRACT}

Background: Due to the high prevalence of arterial hypertension and its role in the development of atherosclerosis, myocardial infarction and stroke, hypertension is a major public health challenge worldwide. There is limited knowledge of the prevalence of hypertension among seafarers who, however, are known to have an excess morbidity and mortality from these disorders. This article addresses the prevalence of hypertension among Danish seafarers and discusses potential risk factors for hypertension in maritime settings.

Materials and methods: A representative sample of 629 Danish seafarers who had statutory medical examinations was studied from the beginning of October 2011 to the end of June 2012. The medical examination included measurements of blood pressure. The prevalence of hypertension in the study population was stratified by age, work place on board, smoking status, alcohol intake, and body mass index. Results: The overall prevalence of hypertension in the study population was $44.7 \%$ (95\% Cl 40.8-48.6). In a comparison sample of adult Danes, the crude rate of hypertension was $12.6 \%$. In addition, $41.8 \%$ (95\% Cl 38.0-45.7) of seafarers were pre-hypertensive. Hypertension was particularly increased among younger seafarers. The proportion of seafarers in antihypertensive treatment was low, in particular among the young seafarers.

Conclusions: Hypertension is a major health issue among Danish seafarers. In addition to ensuring antihypertensive treatment when needed, individual and collective prevention should address lifestyle issues as well as physical and psychosocial exposures at sea.
\end{abstract}

(Int Marit Health 2016; 67, 4: 196-204)

Key words: hypertension, pre-hypertension, seafarers, shift-work, noise on board, Denmark

\section{INTRODUCTION}

Arterial hypertension is globally one of the leading causes of cardiovascular morbidity and mortality such as from myocardial infarction and stroke [1]. Empirical evidence has showed that the risk of cardiovascular diseases (CVD) doubles with an increase of the systolic blood pressure (SBP) by $20 \mathrm{~mm} \mathrm{Hg}$ or the diastolic blood pressure (DBP) by $10 \mathrm{~mm} \mathrm{Hg}$ [2]. Hypertension is estimated to cause 7.5 millionannual deaths, which accounts for around $12.8 \%$ of deaths worldwide [3]. There is strong evidence that hypertension is preventable and that lowering blood pressure (BP) can significantly reduce the prevalence of CVD in hypertensive patients $[4,5]$.

A report from World Health Organisation estimated in 2008 that the overall prevalence of hypertension in adults aged 25 years and over was around 40\%, with considerable variation in between regions [3]. In Denmark, the age-adjusted prevalence of hypertension is $25.7 \%$ [6]. Hypertension is attributed to lifestyle-related as well as work-related risk factors, such as smoking, stress, high fat diet, and low physical activity. These factors determine the risks both in the general population and among seafarers [7].

Seafarers are required to consult a seaman's doctor for medical certification every second year. This medical examination aims to secure the safety of vessels and crews, but it also allows for detection of health problems such as increased BP at an early stage and may thereby contribute to reduce the risk of later overt diseases.

This article presents an empirical study of the prevalence among Danish seafarers of arterial hypertension and 
pre-hypertension and discusses the potential risk factors in the maritime environment.

\section{MATERIALS AND METHODS}

\section{MATERIALS}

The study group consisted of 655 Danish seafarers who were subjected to statutory medical examination [8] from the beginning of October 2011 to the end of June 2012. The enrolled seafarers were examined in four authorised seaman's doctors' clinics in Denmark, one located in Copenhagen, one in Odense and two clinics in Svendborg.

Out of 655 individuals, there was missing information for 26 people about BP $(n=23)$ and age $(n=3)$, resulting in 629 seafarers available for the statistical analysis of the prevalence of hypertension.

The study group was compared with BP measurements stratified by age and gender in a random Danish population sample from Funen [6].

\section{METHODS}

The medical examinations were slightly expanded compared to the legal requirements and involved an interview and a physical examination. Of relevance for this study, the collected data included the seafarers' age, gender, height, weight, medication, workplace on board, and consumption of tobacco and alcohol. In addition, the seafarers had their BP measured with a standard sphygmomanometer. Based on height and weight the body mass index (BMI) was calculated. BMI was interpreted as $<18.5 \mathrm{~kg} / \mathrm{m}^{2}$ underweight, $18.5-24.9 \mathrm{~kg} / \mathrm{m}^{2}$ normal weight, $25-29.9 \mathrm{~kg} / \mathrm{m}^{2}$ overweight, and $\geq 30 \mathrm{~kg} / \mathrm{m}^{2}$ obese.

The seafarers were stratified in 10-year groups with ages ranging from 16 to 77 . Analyses were not conducted by gender but only by age, since the age-adjusted prevalence of hypertension is similar in males and females [6]. $\mathrm{BP} \geq 140 / 90 \mathrm{~mm} \mathrm{Hg}$ was recorded as hypertensive and BP between 120/80 mm Hg and 140/90 mm Hg as pre-hypertensive.

\section{STATISTICAL ANALYSIS}

The data were converted from SPSS ver. 13.0 and analysed by STATA ver. 14.0. Categorical variables were presented as numbers and frequencies (\%). A histogram showed normal distributions of the measured SBP and DBP (Figs. 1, 2). The point prevalence for both hypertension and pre-hypertension was reported for seven age groups and 95\% confidence intervals $(\mathrm{Cl})$ calculated. Further analyses were conducted to study the relation of hypertension and pre-hypertension to BMI, smoking status, alcohol consumption, and work place on board.

\section{INFORMED CONSENT}

This study was conducted in accordance with the Helsinki Declaration and approved by the local Ethics Committee (Ref. no. S-20110039). All participants signed informed consent before the medical examination.

\section{RESULTS}

The distribution of DBP and SBP is illustrated in Figures 1 and 2. Out of 629 seafarers, 281 (44.7\%) were hypertensive, while 263 (41.8\%) were pre-hypertensive (Table 1). The age-specific prevalence of hypertension ranged from $28.6 \%$ in the youngest group ( $<20$ years old) to $68.9 \%$ in the 60-69 years old group (Table 1, Fig. 3). There were major differences between the prevalence of hypertension in each age-group in the study population and the age-stratified prevalence in the reference Danish population (Fig. 3) [6]. The crude prevalence of hypertension in the latter was $12.6 \%$ (95\% Cl 11.9-13.4\%).

According to self-reports, only $15.0 \%(95 \% \mathrm{Cl} 11.2-$ $-19.6 \%)$ of the hypertensive seafarers received treatment for hypertension. The remaining majority of hypertensive individuals (83.6\%) were not in antihypertensive medication. In contrast 59.0\% (95\% Cl 55.9-62.1\%) of the hypertensive subjects in the control group received antihypertensive medication [6]. The self-reported treatment of hypertension in the different age groups varied greatly with young seafarers particularly undertreated (Fig. 4).

The studied sample of seafarers covered all workplaces on board (Fig. 5) and the prevalence of hypertension differed in between them (Table 2). Almost half of the seafarers who worked in the engine room had hypertension, followed by those who worked on deck.

There was slightly less hypertension in non-smokers than in former and current smokers. The highest prevalence was found in former smokers. Seafarers who consume more than 15 alcoholic beverages weekly had the highest prevalence of hypertension (Table 2).

The prevalence of hypertension increased with rising BMI (Fig. 6). Seafarers of normal weight had the smallest prevalence of hypertension, while the prevalence of hypertension in overweight and obese seafarers was $68.0 \%$ (Table 2). There was a high rate of overweight (38.3\%) and obese (18.9\%) seafarers in the studied sample. Only $44.4 \%$ were underweight or had normal weight (Table 3).

\section{DISCUSSION}

This study has demonstrated a high and worrying prevalence of hypertension among Danish seafarers. The prevalence is more than three times the prevalence in the general Danish population. The study population was mainly male seafarers (89.5\%), and because the prevalence of hyper- 


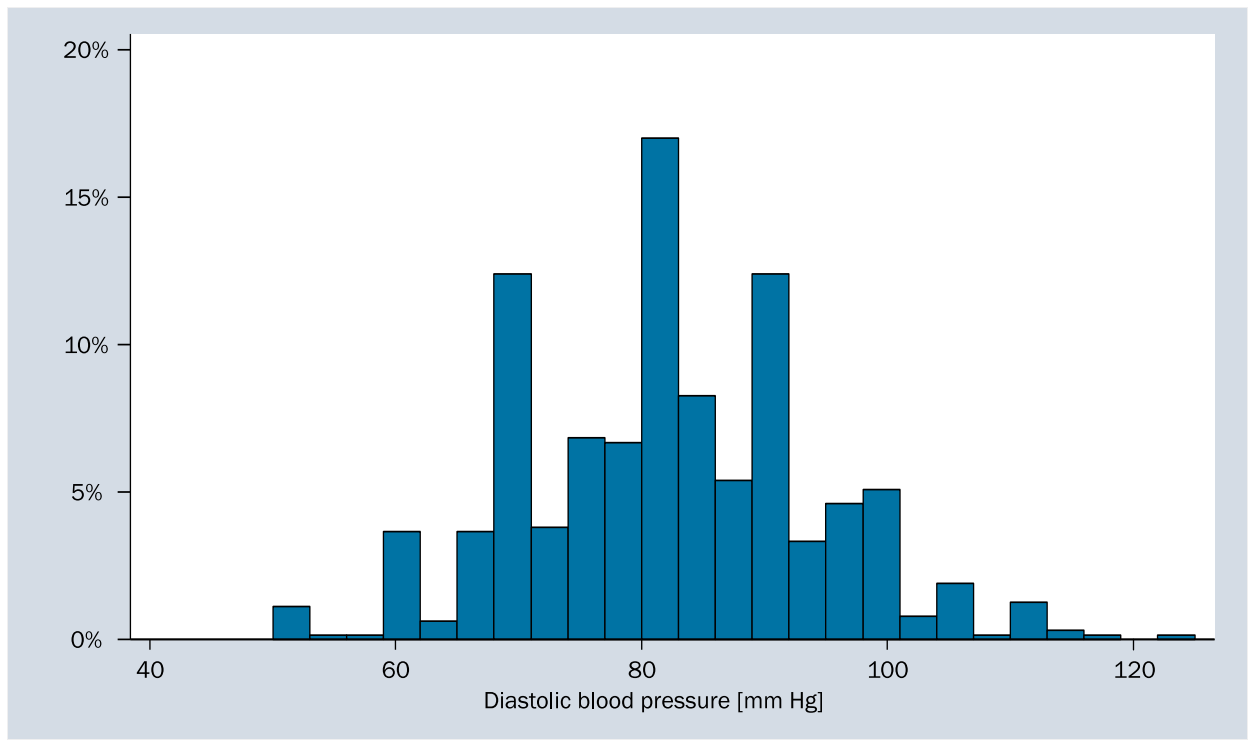

Figure 1. The distribution of diastolic blood pressure

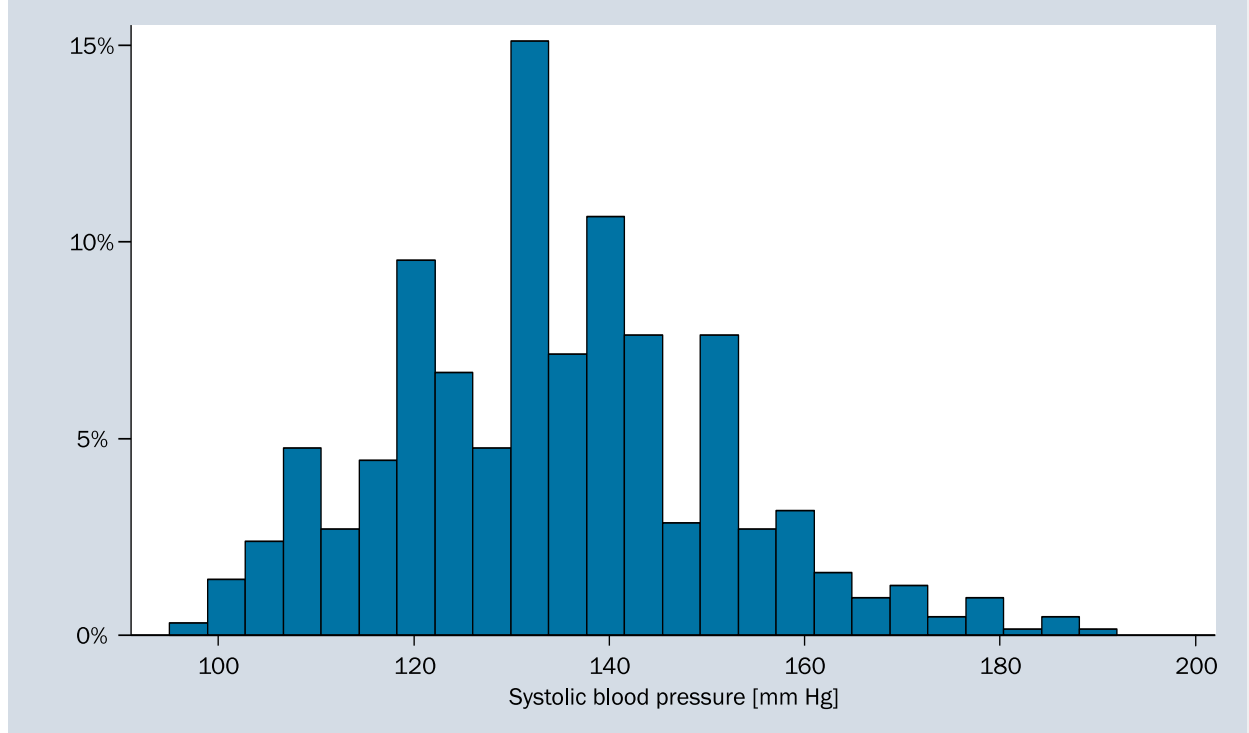

Figure 2. The distribution of systolic blood pressure

Table 1. Age-specific prevalence of hypertension, pre-hypertension, and treatment

\begin{tabular}{lllll}
\hline Age & $\begin{array}{l}\text { Number of } \\
\text { seafarers }\end{array}$ & $\begin{array}{l}\text { Prevalence of hypertension } \\
{[\%](\mathbf{9 5 \%} \mathbf{C l})}\end{array}$ & $\begin{array}{l}\text { Prevalence of pre-hyper- } \\
\text { tension [\%] (95\% Cl) }\end{array}$ & $\begin{array}{l}\text { Prevalence of treatment [\%] } \\
(\mathbf{9 5 \%} \mathbf{~ C I})\end{array}$ \\
\hline$<20$ & 21 & $28.6(13.1-51.4)$ & $42.9(23.6-64.6)$ & 0 \\
$20-29$ & 186 & $33.3(26.9-40.4)$ & $47.3(40.2-54.5)$ & 0 \\
$30-39$ & 148 & $38.5(31.0-46.6)$ & $49.3(41.3-57.4)$ & $2.7(1-7)$ \\
$40-49$ & 122 & $44.3(35.7-53.2)$ & $38.5(30.3-47.5)$ & $4.9(2.2-10.6)$ \\
$50-59$ & 105 & $66.7(57.1-75.1)$ & $30.5(22.4-40.0)$ & $22.9(15.8-31.9)$ \\
$60-69$ & 45 & $68.9(53.9-80.8)$ & $28.9(17.5-43.8)$ & $37.8(24.8-52.8)$ \\
$70-79$ & 2 & $50.0(1.9-98.1)$ & $50.0(1.9-98.1)$ & 100 \\
All ages & 629 & $44.7(40.8-48.6)$ & $41.8(38.0-45.7)$ & $8.4(6.5-10.9)$
\end{tabular}




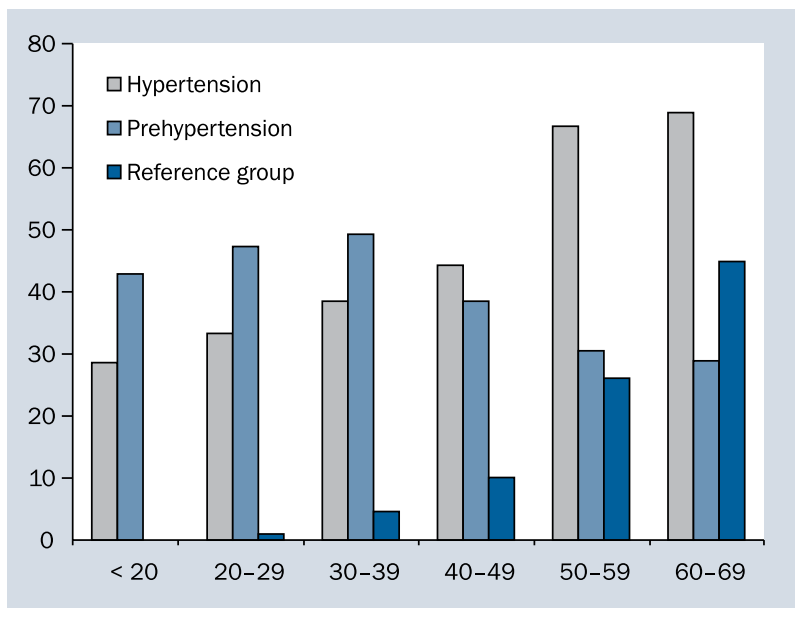

Figure 3. The prevalence of hypertension and pre-hypertension in the study population of seafarers compared to the prevalence of hypertension in the reference population [6]

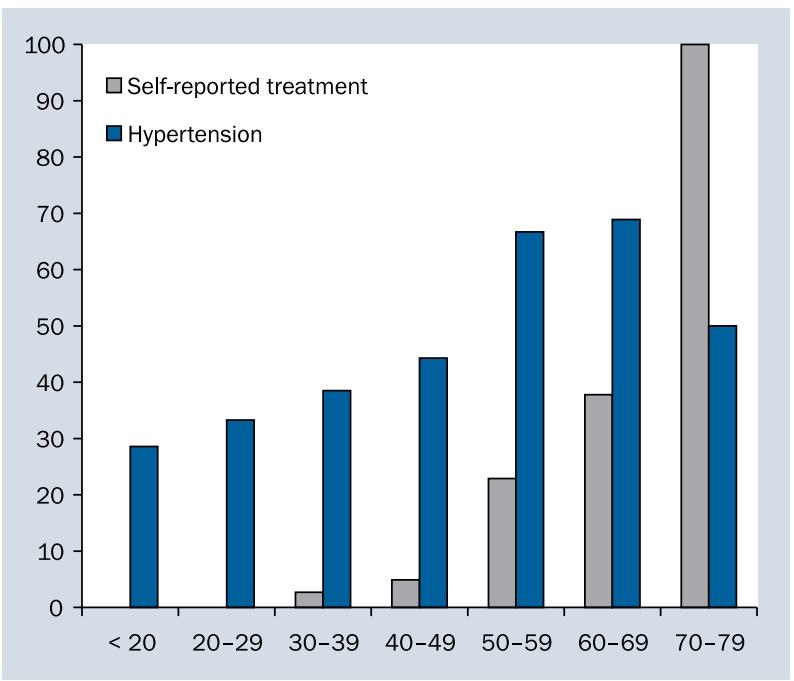

Figure 4. The proportion of hypertensive seafarers and the proportion of hypertensive seafarers in antihypertensive medication stratified by age

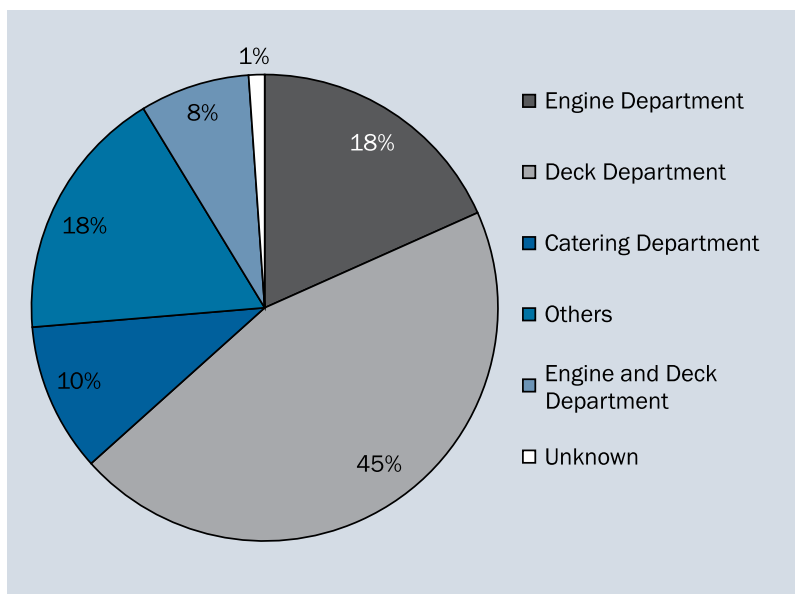

Figure 5. Distribution of seafarers with regard to work place on board (\%) tension is less influenced by gender [6] we have looked at male and female seafarers together but stratified by age. In all age-strata the prevalence of hypertension was much higher in seafarers than in control subjects. The prevalence of hypertension increased with age in both groups. It is, however, of particular concern that young seafarers were much more likely to be hypertensive than the general young population (Fig. 3). With $41.8 \%$ of the study population pre-hypertensive, only 85 (13.5\%) of the studied 629 seafarers had a normal BP measured at the medical examination. One explanation of this finding is the high rate of overweight across all age groups (Table 3). The rate of overweight among seafarers has increased during the last decades, and today, Danish maritime students are more overweight than their peers even before they start to work at sea [9].

Arterial hypertension is a severe challenge globally, and the maritime setting appears to be a high-risk workplace for the development of hypertension. We believe that the studied sample is representative of Danish seafarers, and further that our findings can be generalised so that a high rate of hypertension is also likely to exist among seafarers in a global context who share similar maritime exposures and lifestyles as the Danish seafarers. This is supported by a French study that found significantly increasing prevalence of hypertensive seafarers from $14.8 \%$ the 1990 s to $42.1 \%$ in the 2000s [10]. With a prevalence exceeding $40 \%$, hypertension is also common in Spanish seafarers [11].

We have demonstrated that the majority of hypertensive seafarers in the studied sample did not receive antihypertensive medication. In fact, compared to hypertensive seafarers, seven times as many hypertensive subjects in the control group of Danes were in treatment [6]. A Danish population study based on BP data collected in 1998-1999 found a much higher prevalence of hypertension (38.5\%) than today [12]. The previous prevalence of hypertension among Danes is comparable to the findings in today's seafarers. It is also noticeable that less than $1 / 4$ were in antihypertensive treatment at the time [12], which also suggests challenges similar to those experienced by Danish seafarers. This high prevalence in the seafarers of hypertension and the low rate of antihypertensive treatment suggests the incapability of the health service to reach this population. However, it should be emphasized that pharmacological treatment may not always be indicated with minor increase of BP, and that in particular young people may as well benefit from lifestyle changes [13].

Hypertension is one of the main risk factors for CVD. There is an increased hospitalisation rate of CVD in seafarers [14]. CVD represent the most common cause of seafarers' death at sea. Up to $80 \%$ of disease-related deaths at sea have been attributed to diagnosed or presumed myocardial infarction [15]. Studies from United Kingdom 
Table 2. The prevalence of hypertension in 629 seafarers

\begin{tabular}{|c|c|c|c|c|}
\hline Variable & $\begin{array}{l}\text { Number of } \\
\text { seafarers }\end{array}$ & $\begin{array}{l}\text { Number of hyper- } \\
\text { tensive seafarers }\end{array}$ & Proportion [\%] & $\begin{array}{l}95 \% \text { confidence } \\
\text { interval }\end{array}$ \\
\hline \multicolumn{5}{|l|}{ Work place on board } \\
\hline Engine Department & 115 & 57 & 49.6 & $40.5-58.7$ \\
\hline Deck Department & 283 & 126 & 48.1 & $42.3-53.9$ \\
\hline Catering Department & 65 & 21 & 32.3 & $22.0-44.7$ \\
\hline Others & 111 & 41 & 36.9 & $28.4-46.3$ \\
\hline Both engine and deck & 48 & 22 & 45.8 & $32.6-60.0$ \\
\hline Missing information & 7 & 4 & 57.1 & $20.9-87.1$ \\
\hline \multicolumn{5}{|l|}{ Smoking status } \\
\hline Non-smoker & 243 & 95 & 39.1 & $33.1-45.4$ \\
\hline Current smoker & 150 & 65 & 43.3 & $35.6-51.4$ \\
\hline Former smoker & 121 & 59 & 48.8 & $39.9-57.7$ \\
\hline Unknown & 115 & 49 & 42.9 & $12.9-79.1$ \\
\hline \multicolumn{5}{|c|}{ Alcohol consumption at home } \\
\hline Never & 54 & 25 & 46.3 & $33.4-59.7$ \\
\hline 1-7 beverages & 243 & 94 & 38.7 & $32.7-45.0$ \\
\hline $8-14$ beverages & 115 & 44 & 38.3 & $29.8-47.5$ \\
\hline$>15$ beverages & 94 & 52 & 55.3 & $45.1-65.1$ \\
\hline Unknown & 123 & 51 & 41.7 & $17.7-70.4$ \\
\hline \multicolumn{5}{|l|}{ Body mass index } \\
\hline Underweight & 5 & 2 & 40.0 & $8.2-83.2$ \\
\hline Normal weight & 256 & 72 & 28.1 & $22.9-34.0$ \\
\hline Overweight & 241 & 125 & 51.9 & $45.5-58.1$ \\
\hline Obese & 109 & 76 & 69.7 & 60.4- 77.7 \\
\hline Missing information & 18 & 6 & 33.3 & $15.4-57.9$ \\
\hline
\end{tabular}

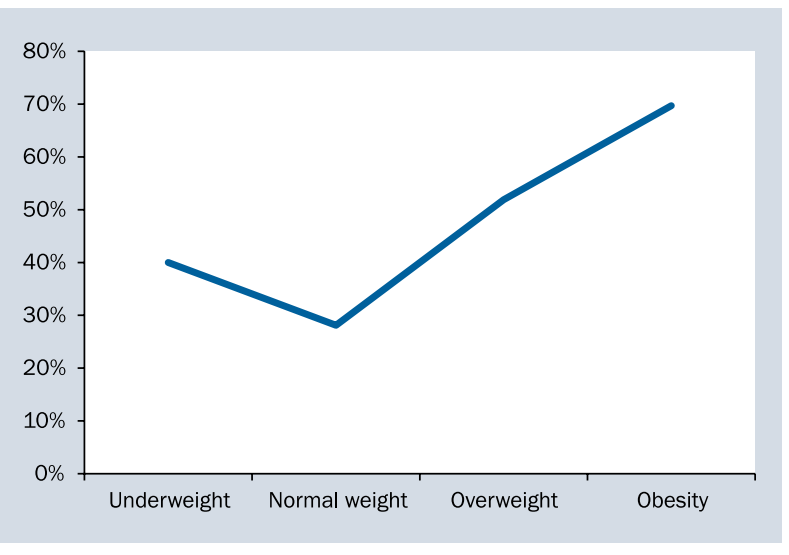

Figure 6 . The relation between hypertension (\%) and body mass index

[16] and Denmark [17] have showed mortality rates of CVD of 43.4 and 27.9 per 100,000 seafarer-years, accounting for $71 \%$ and $55 \%$, respectively, of natural deaths on board.
On top of that a significant number of cerebrovascular deaths can be related to hypertension. Failing to adhere to antihypertensive therapy increases the risk of fatal stroke in hypertensive individuals [5]. The situation has improved since then but remains concerning $[18,19]$.

In Denmark, the seamen's doctor is usually not the seafarer's general practitioner. The seamen's doctors' tasks are rather that of an executive health officers working on behalf of the Danish Maritime Authority. The purpose of the statutory medical "fit for duty" examination every second year is to ensure the individual seafarer's health and the safety of the ship. Therefore the assessment considers whether a certain disease or condition can cause an increased risk of acute complications that cannot be handled by a layman on board, and therefore may pose a significant risk for the seafarer. In addition, the examination should consider if sudden illness of a seafarer poses a risk to the safety or put other crew members in a needlessly difficult situation, and whether the condition causes difficulties 
Table 3. The proportion of overweight and obesity stratified by age

\begin{tabular}{|c|c|c|c|c|c|c|}
\hline Age & $\begin{array}{l}\text { Number of over- } \\
\text { weight seafarers }\end{array}$ & Proportion [\%] & $\begin{array}{l}95 \% \text { confidence } \\
\text { interval }\end{array}$ & $\begin{array}{l}\text { Number of obese } \\
\text { seafarers }\end{array}$ & Proportion [\%] & $\begin{array}{l}95 \% \text { confidence } \\
\text { interval }\end{array}$ \\
\hline$<20$ & 0 & - & - & 1 & 4.7 & $0.6-28.2$ \\
\hline $20-29$ & 51 & 27.4 & $21.5-34.3$ & 14 & 7.5 & $4.5-12.3$ \\
\hline $30-39$ & 62 & 41.9 & $34.1-50.0$ & 25 & 16.9 & $11.7-23.8$ \\
\hline $40-49$ & 57 & 46.7 & $38.0-55.6$ & 26 & 21.3 & $14.9-29.5$ \\
\hline $50-59$ & 46 & 43.8 & $34.6-53.5$ & 31 & 29.5 & $21.5-39.0$ \\
\hline $60-69$ & 24 & 53.3 & $38.7-67.4$ & 11 & 24.4 & $14.0-39.2$ \\
\hline $70-79$ & 1 & 50.0 & $1.9-98.0$ & 1 & 50.0 & $1.9-98.0$ \\
\hline
\end{tabular}

for the seafarer to cope with an emergency on board. The examination provides an opportunity for detecting, treating and preventing any revealed deviations from health. But it seems that this option is only applied to a limited extent. For example, in Denmark, seafarers are not grounded, unless the SBP/DBP exceeds 180-200/110 mm Hg [20]. According to the American Heart Association, a BP on this level is very high and represents a medical emergency a hypertensive crisis [21]. International Maritime Organisation have suggested lower limits (SBP/DBP 160/100 mm Hg) [22], which, however, is equivalent to hypertension stage 2 [21], which also represents a dangerous condition. The application of lower limits would most likely result in more seafarers being treated, so that they can safely continue their work at sea. It has indeed been suggested to include a cardiovascular risk assessment in the medical examination of seafarers for preventive purposes [13].

Seafarers may not visit their family doctors often due to long working periods at sea. For that reason it is particularly important that the seamen's doctors inform the seafarers about any concerning observation found in connection with the statutory medical examination and encourage the seafarer to consult his family doctor for control and indicated treatment. Pre-hypertensive and in particular hypertensive seafarers should be informed about the level of their BP and what that means in terms of health and management.

It is not in the explicit role of the seamen's doctors to follow up the health of the seafarers unless according to regulations adverse health prevents work at sea. Whether seafarers are informed about increased BP that is less than the limit of $180 \mathrm{~mm} \mathrm{Hg}$ systolic/110 $\mathrm{mm} \mathrm{Hg}$ diastolic is not known. According to Figures 1 and 2, a BP of that level is rare while increased lower stages of hypertension are very common. Even if informed about a high BP, the seafarer may not be able to follow a given advice regarding control/ treatment, e.g. if the seafarer has to board immediately. After boarding, the seafarer will be distant from professional health care. The limited treatment options on board focus on acute rather than chronic conditions, and control and treatment of hypertension is not within the scope of medical care on board [23]. Awareness and treatment of hypertension has been found to be associated with female sex, diabetes, CVD, age, contact to the general practitioner, diet and BMI [12]. Therefore, it is not surprising that the studied population of seafarers is disfavoured.

\section{RISK FACTORS ON BOARD}

A multitude and combinations of risk factors on board can have an adverse health effect on seafarers' cardiovascular health $[7,10,11,24]$ and lead to elevated BP in seafarers [24-26]. Health consequences such as overweight and diabetes are other frequent consequences of life at sea that are related to hypertension [8].

Food. In spite of the fact that the seafarers' food is vital to their health [24] they have limited choices for healthy food on board. Overweight, which is an essential risk factor for the development of hypertension [27], becomes a frequent and severe problem among seafarers. An increase in BMI of about $10.3 \mathrm{~kg} / \mathrm{m}^{2}$ doubles the risk of hypertension [28]. A German study showed that $64 \%$ of seafarers were overweight, and that $16 \%$ of 351 male seafarers had a BMI in excess of $30 \mathrm{~kg} / \mathrm{m}^{2}$ [24]. A recent Danish study found even more alarming figures with $66 \%$ overweight seafarers, and that maritime students who enter the maritime business are already more overweight than other young people [9].

Sedentary work. Sedentary lifestyle is also an increasing challenge in modern seafaring. Low energy expenditure is related to prolonged sitting during work and in leisure time at sea [29]. There is a positive association between sedentary behaviours and hypertension, and individuals without daily physical exercise have a 20-50\% higher risk of developing hypertension [30].

Shift-work. Irregular work poses a threat to health [31]. Many seafarers have to work in shifts to keep the vessel going. Shift work contributes to development of hypertension [32], not only by causing persistently elevated acute $\mathrm{BP}$, but also by delaying BP recovery [32]. 
Table 4. Exposure limits in different work area on board and on land

\begin{tabular}{lllll}
\hline Area & Control room & Office & Dining rooms & Sleeping area \\
\hline IMO noise limit $(\mathrm{dB})[36]$ & 75 & 65 & 65 & 60 \\
Noise limit land $(\mathrm{dB})[37]$ & 55 & 55 & 55 & 45
\end{tabular}

IMO - International Maritime Organisation

Noise. Exposure to road noise and nighttime aircraft noise is associated with high $\mathrm{BP}[33,34]$, and it has been shown that the noise level in the workplace is proportional to the prevalence of hypertension [35]. Noise exposure of vessels' crews at sea is inevitable, and seafarers have to suffer from $24 \mathrm{~h}$ of daily background noise for several months on board. Measured noise levels are highest in the engine rooms, followed by the levels on deck [25]. This may partly explain the high prevalence of hypertension for seafarers working in these two areas. Noise can be stressful and disrupt sleep. A noise level of $40 \mathrm{~dB}$ to $50 \mathrm{~dB}$ is annoying during sleep, while $70 \mathrm{~dB}$ will disrupt the sleep for everyone. The main sources of mechanically created noise and vibration are the engines. The International Maritime Organisation regulates the maximum noise limits on board vessels [36], which, however, is higher than on land (Table 4) [37].

\section{LIMITATIONS OF THE STUDY}

The major limitation of this study is the potential of flawed BP measurements, which may occur on several levels. Details regarding how the seafarers' doctors measured the BP's in this study are not known from the records. The BP measurements represented one-time checks in the clinics and may be influenced by personal factors such as poor sleep the previous night [38], emotions, and the effect of nicotine or drugs etc. and measurements may therefore overestimate the prevalence of hypertension and pre-hypertension [39]. Additional details regarding standards for measurement may apply and can vary in between the four clinics. One example is the potential of having different BP in the two arms. Generally, a difference within $10 \mathrm{~mm} \mathrm{Hg}$ is regarded as acceptable [40]. However, we do not know the seaman's doctors' preferences, and it is unlikely that the recorded BP represents the mean value for both arms. Preparation of the subject before measurement of BP should involve positioning of the arm, and avoiding muscle tension, talking and background noise. Clothing that covers the location of cuff placement should be removed, and the individual should be comfortably seated, with legs uncrossed, and the back and arm supported so that the middle of the cuff on the upper arm is at the level of the midpoint of sternum. The patients should be instructed to relax and to not talk. Ideally $5 \mathrm{~min}$ should elapse before the first reading [39]. A "white coat effect" can occur at any age and is common in most patients. It can, however, hardly cause major distortion of our results. In the control sample $14.4 \%$ were hypertensive according to the initial screening. This figure was only slightly reduced to $12.6 \%$ at subsequent BP measurements at home [6]. Lastly, the size of the applied cuff can influence BP measurements. An inappropriate cuff size leads to an inaccurate measurement of the BP [41, 42]. The cuff choice should reflect anthropometry such as the upper arm size. A too narrow cuff bladder width leads to an overestimation of $\mathrm{BP}$, and a too wide bladder underestimate the true BP $[43,44]$. The choice of an appropriate cuff size should be particularly considered for this group of seafarers, since $53.9 \%$ of them are overweight or obese. Such errors may result in higher readings of BP and consequently a higher prevalence of hypertension and pre-hypertension.

\section{CONCLUSIONS}

The prevalence of hypertension among Danish seafarers is much higher than in the reference group of Danes, and particularly prominent in the younger age groups. The low rate of treatment indicates the need of further awareness and control of hypertension among seafarers. Seafaring is associated with specific risk factors that affects BP and can contribute to hypertension among seafarers. The role of lifestyle issues such as physical exercise, healthy food, and smoking should be communicated to the seafarers but cannot stand alone. In addition to individual counselling and management of seafarers with hypertension (and pre-hypertension), there is a need of collective mitigation at sea which should be a company responsibility. Such preventive activity should target the many risk factors at sea that are part of the maritime environment such as nutrition, sedentary lifestyle, noise and fatigue.

\section{REFERENCES}

1. Ezzati M, Lopez AD, Rodgers A, Vander Hoorn S, Murray CJ, Group CRAC. Selected major risk factors and global and regional burden of disease. Lancet 2002; 360: 1347-1360. doi:10.1016/S01406736(02)11403-6.

2. Prevention, detection, evaluation, and treatment of hypertension. The Sixth Report of the Joint National Committee. National Institutes of Health-National Heart, Lung, and Blood Institute. National High Blood Pressure Education Programme. Indian Heart J 1999; 51: 381-396.

3. Raised blood pressure: World Health Organization 2016 [cited 2016 25 July]. Available from: http://www.who.int/gho/ncd/risk_factors/ blood_pressure_prevalence_text/en/. 
4. Turnbull F, Collaboration BPLTT. Effects of different blood-pressure-lowering regimens on major cardiovascular events: results of prospectively-designed overviews of randomised trials. Lancet 2003; 362: 1527-1535.

5. Herttua K, Martikainen P, Batty GD, Kivimaki M. Poor adherence to statin and antihypertensive therapies as risk factors for fatal stroke. J Am Coll Cardiol 2016; 67: 1507-1515. doi:10.1016/j. jacc.2016.01.044.

6. Kronborg CN, Hallas J, Jacobsen IA. Prevalence, awareness, and control of arterial hypertension in Denmark. J Am Soc Hypertens 2009; 3: 19-24 e2. doi:10.1016/j.jash.2008.08.001.

7. Oldenburg M. Risk of cardiovascular diseases in seafarers. Int Marit Health 2014; 65: 53-57. doi:10.5603/IMH.2014.0012.

8. Moller Pedersen SF, Jepsen JR. The metabolic syndrome among Danish seafarers. Int Marit Health 2013; 64: 183-190.

9. Hansen HL, Hjarnoe L, Jepsen JR. Obesity continues to be a major health risk for Danish seafarers and fishermen. Int Marit Health 2011; 62: 98-103.

10. Pougnet R, Pougnet L, Lodde BL et al. Cardiovascular risk factors in seamen and fishermen: review of literature. Int Marit Health 2013; 64: 107-113.

11. Romero-Paredes MdC, Reinoso-Barbero L, Gonzalez-Gomez MF, Bandres-Moya F. Improving cardiovascular health in Spanish seafarers. Int Marit Health 2016; 67: 3-8. doi: 10.5603/IMH.2016.0002.

12. Sehestedt T, Ibsen H, Jorgensen T. Awareness, treatment and control of hypertension in Denmark. The Inter99 study. Blood Press 2007; 16: 312-319. doi:10.1080/08037050701428307.

13. Rosik E, Jaremin B, Szymanska K. Can general cardiovascular risk evaluation facilitate the assessment of fitness for work and contribute to the reduction of cardiovascular incidents among seamen and fishermen? Article for discussion. Int Marit Health 2006; 57: 188-197.

14. Poulsen TR, Burr H, Hansen HL, Jepsen JR. Health of Danish seafarers and fishermen 1970-2010: What have register-based studies found? Scand J Public Health 2014; 42: 534-545. doi: 1403494814534538 , [pii] 10.1177/1403494814534538.

15. Jaremin B, Kotulak E. Myocardial infarction (MI) at the work-site among Polish seafarers. The risk and the impact of occupational factors. Int Marit Health 2003; 54: 26-39.

16. Roberts SE. Mortality from disease among seafarers in British merchant shipping (1976-1995). Int Marit Health 2002; 53: 43-58.

17. Hansen HL. Surveillance of deaths on board Danish merchant ships, 1986-1993: implications for prevention. Occup Environ Med 1996; 53: $269-275$.

18. Borch DF, Hansen HL, Burr H, Jepsen JR. Surveillance of maritime deaths on board Danish merchant ships, 1986-2009. Int Marit Health 2012; 63: 7-16.

19. Roberts SE, Hansen HL. An analysis of the causes of mortality among seafarers in the British merchant fleet (1986-1995) and recommendations for their reduction. Occup Med (Lond) 2002; 52: 195-202.

20. Order of medical examinations of seafarers and fishermen, Copenhagen: Danish Maritime Authority; 2013 [updated 12 August 2013; cited 201625 July]. Available from: http://www.dma.dk/sitecollectiondocuments/legislation/orders/2013/bek-999-12082013-laegeundersoegelse af soefarende.pdf.

21. Understanding Blood Pressure Readings: American Heart Association; 2014 [cited 201625 July]. Available from: http://www.heart. org/HEARTORG/Conditions/HighBloodPressure/AboutHighBloodPressure/Understanding-Blood-Pressure-Readings_UCM_301764_ Article.jsp - .V5W_2478S3M.
22. Guidelines on the medical examination of seafarers, London: International Maritime Organization; 2013 [cited 201625 July]. Available from: http://www.safety4sea.com/images/media/pdf/IMO-Guidelines_on_the_Medical_Examination_of_the_Seafarers.pdf.

23. Oldenburg M, Baur X, Schlaich C. Cardiovascular diseases in modern maritime industry. Int Marit Health 2010; 62: 101-106.

24. Oldenburg M, Harth V, Jensen HJ. Overview and prospect: food and nutrition of seafarers on merchant ships. Int Marit Health 2013; 64: 191-194.

25. Sunde E, Irgens-Hansen K, Moen BE, Gjestland T, Koefoed VF, Oftedal $\mathrm{G}$, et al. Noise and exposure of personnel aboard vessels in the Royal Norwegian Navy. Ann Occup Hyg 2015; 59: 182-199. doi: 10.1093/annhyg/meu075.

26. Jepsen JR, Zhao Z, van Leeuwen WM. Seafarer fatigue: a review of risk factors, consequences for seafarers' health and safety and options for mitigation. Int Marit Health 2015; 66: 106-117. doi: 10.5603/IMH.2015.0024.

27. Jezewska M, Babicz-Zielinska E, Leszczynska I, Grubman M. Promotion of healthy nutrition of seafarers. Int Marit Health 2009; 60: 48-50.

28. Poorolajal J, Farbakhsh F, Mahjub H, Bidarafsh A, Babaee E. How much excess body weight, blood sugar, or age can double the risk of hypertension? Public Health 2016; 133: 14-18. doi: 10.1016/j. puhe.2015.10.014.

29. Tremblay MS, Colley RC, Saunders TJ, Healy GN, Owen N. Physiological and health implications of a sedentary lifestyle. Appl Physiol Nutr Metab 2010; 35: 725-740. doi: 10.1139/H10-079.

30. Beunza JJ, Martinez-Gonzalez MA, Ebrahim S et al. Sedentary behaviors and the risk of incident hypertension: the SUN Cohort. Am J Hypertens 2007; 20: 1156-1162. doi: 10.1016/j.amjhyper.2007.06.007.

31. Barton J, Folkard S, Smith L, Poole CJ. Effects on health of a change from a delaying to an advancing shift system. Occup Environ Med 1994; 51: 749-755.

32. Su TC, Lin LY, Baker D et al. Elevated blood pressure, decreased heart rate variability and incomplete blood pressure recovery after a 12-hour night shift work. J Occup Health 2008; 50: 380-386.

33. Jarup L, Babisch W, Houthuijs D et al. Hypertension and exposure to noise near airports: the HYENA study. Environ Health Perspect 2008; 116: 329-333. doi: 10.1289/ehp.10775.

34. van Kempen $\mathrm{E}$, Babisch W. The quantitative relationship between road traffic noise and hypertension: a meta-analysis. J Hypertens 2012; 30: 1075-1086. doi: 10.1097/HJH.0b013e328352ac54.

35. de Souza TC, Perisse AR, Moura M. Noise exposure and hypertension: investigation of a silent relationship. BMC Public Health 2015; 15: 328. doi: 10.1186/s12889-015-1671-z.

36. Maritime Safety Committee agrees new measures for passenger ship safety and protection of personnel from noise on-board ships (2012).

37. Night Noise Guidelines for Europe, Bonn: World Health Organization; 2007 [cited 201625 July]. Available from: http://ec.europa.eu/ health/ph_projects/2003/action3/docs/2003_08_frep_en.pdf.

38. Calhoun DA, Harding SM. Sleep and hypertension. Chest 2010; 138 : 434-443. doi: 10.1378/chest.09-2954.

39. Pickering TG, Hall JE, Appel $\sqcup$ et al. Recommendations for blood pressure measurement in humans and experimental animals: part 1: blood pressure measurement in humans: a statement for professionals from the Subcommittee of Professional and Public Education of the American Heart Association Council on High Blood Pressure Research. Circulation 2005; 111: 697-716. doi: 10.1161/01. CIR.0000154900.76284.F6. 
40. How to Monitor and Record Your Blood Pressure: American Heart Association; 2014 [cited 201625 July]. Available from: http:// www.heart.org/HEARTORG/Conditions/HighBloodPressure/ SymptomsDiagnosisMonitoringofHighBloodPressure/How-to-Monitor-and-Record-Your-Blood-Pressure_UCM_303323_Article.jsp - .V5YWzI78S3N.

41. Bakx C, Oerlemans G, van den Hoogen H, van Weel C, Thien T. The influence of cuff size on blood pressure measurement. J Hum Hypertens 1997; 11: 439-445.
42. Gomez-Marin O, Prineas RJ, Rastam L. Cuff bladder width and blood pressure measurement in children and adolescents. J Hypertens 1992; 10: 1235-1241.

43. Jones DW, Appel $\sqcup$, Sheps SG, Roccella EJ, Lenfant C. Measuring blood pressure accurately: new and persistent challenges. JAMA 2003; 289: 1027-1030.

44. O'Brien E, Beevers G, Lip GY. ABC of hypertension: Blood pressure measurement. Part IV-automated sphygmomanometry: self blood pressure measurement. BMJ 2001; 322: 1167-1170. 